\title{
Development of low-power loss Mn-Zn ferrites using microwave sintering method
}

\author{
S R MURTHY \\ Department of Physics, Osmania University, Hyderabad 500 007, India
}

MS received 15 March 2002; revised 12 June 2003

\begin{abstract}
Microwave sintering (MS) method has been successfully used for densifying Mn-Zn ferrites used for high frequency applications. This method needs only a short time to obtain high density when compared to conventionally sintered (CS) Mn-Zn ferrites. The lowest power loss was also achieved at $100 \mathrm{kHz}$ and $200 \mathrm{mT}$ condition for the microwave sintered samples. Conductor-embedded ferrite transformers were constructed using CS and MS samples and output power, efficiency, and surface rise of temperature were measured at sinusoidal voltage of $25 \mathrm{~V}$ with frequency, $1 \mathrm{MHz}$. The efficiency and surface rise of temperature of transformer were found to be high and low, respectively.
\end{abstract}

Keywords. Ferrites; microwave sintering; conventional sintering; power loss; hysteresis loss; eddy current loss; transformer; high frequency applications.

\section{Introduction}

A reduction in size and weight of power supplies can be achieved by using switched mode or resonant concepts. For the voltage conversion several circuit designs are in use with ferrites as transformer core materials. Transformer ferrites must show low energy losses at high induction levels at higher and higher frequencies (Globus 1977; Snelling and Giler 1983; Goldman 1990; Stopples 1996; Yasuhara and Takagawa 2000). This requires development of new ferrite materials with constantly improving loss characteristics.

To reduce power loss, both hysteresis loss and eddy current loss should be suppressed by available processing techniques. In this connection, it was found that the microwave sintering technique markedly enhanced the densification rate at lower sintering temperature of the material. In this technique the materials can absorb the microwaves and self-generate heat (Ruginets and Fischer 1995; Lin et al 1997; Lee and Case 1999).

$\mathrm{Mn}-\mathrm{Zn}$ ferrite has been selected as a material of choice due to its high saturation magnetization and low power loss for high frequency applications. The microwave sintering technique has been used in the preparation of $\mathrm{Mn}-$ $\mathrm{Zn}$ ferrites. The magnetic properties and power losses are measured and the results obtained are compared with those of conventionally sintered $\mathrm{Mn}-\mathrm{Zn}$ ferrites.

\section{Experimental}

High purity polycrystalline samples were prepared by using a microwave method. Pure (99.99\%) $\mathrm{MnO}, \mathrm{ZnO}$ and $\mathrm{Fe}_{2} \mathrm{O}_{3}$ powders with different particle sizes were used for the preparation. The $\mathrm{K}-\mathrm{Fe}_{2} \mathrm{O}_{3}$ coarse particles (average diameter, $0.13 \mu \mathrm{m}$ ) were synthesized by oxidation of $\mathrm{Fe}_{3} \mathrm{O}_{4}$ particles at $800^{\circ} \mathrm{C}$. Industrial grade particles of magnesium oxide and zinc oxide were used as the coarse particles with average diameters of $0.8 \mu \mathrm{m}$ and $0.15 \mu \mathrm{m}$, respectively. Fine particles of magnesium oxide and zinc oxide were synthesized by thermal decomposition of manganese oxalate and zinc oxalate at $400^{\circ} \mathrm{C}$ in air. These powders were mixed together with wet attrition milling. Their molar ratio was adjusted to obtain the composition: $\mathrm{Mn}_{0.66} \mathrm{Zn}_{0.27} \mathrm{Fe}_{2} \mathrm{O}_{4}$. The powder was made into batches. One batch of powder was calcined at $800^{\circ} \mathrm{C}$ for $4 \mathrm{~h}$ using the high temperature furnace. The second batch of samples were calcined at $800^{\circ} \mathrm{C}$ for $30 \mathrm{~min}$ in microwave furnace. The microwave sintering process was carried out using a specially designed applicator which consists of a domestic microwave oven having an output power level tunable up to a maximum of $800 \mathrm{~W}$ and operating frequency of $2.45 \mathrm{GHz}$. Then the powder was re-ground by wet ball milling for $10 \mathrm{~h}$ to form slurry. To this powder, $2 \mathrm{wt} \%$ poly-vinyl-alcohol was added as a binder. The granules were compacted at a pressure of $190 \mathrm{MPa}$ for $10 \mathrm{~min}$, into discs, rods and toroidal shape samples. The specimens were heated up to $400^{\circ} \mathrm{C}$ to remove the binder and the lubricant. Finally, the samples were sintered using two techniques. The batch one samples were conventionally sintered $(\mathrm{CS})$ at $1050^{\circ} \mathrm{C} / 10 \mathrm{~h}, 1100^{\circ} \mathrm{C} / 10 \mathrm{~h}, 1150^{\circ} \mathrm{C} /$ $10 \mathrm{~h}$, and $1200^{\circ} \mathrm{C} / 10 \mathrm{~h}$. The second batch of samples was sintered using the microwave sintering (MS) method at $1050^{\circ} \mathrm{C} / 20 \mathrm{~min}, 1100^{\circ} \mathrm{C} / 20 \mathrm{~min}, 1150^{\circ} \mathrm{C} / 20 \mathrm{~min}$ and $1200^{\circ} \mathrm{C} / 20 \mathrm{~min}$ in air. The sintering temperature in both 
the techniques was measured using a pt-13\% pt-Rh thermocouple with an accuracy of $\pm 1^{\circ} \mathrm{C}$. The rate of heating and cooling during microwave sintering and conventional sintering are $20^{\circ} \mathrm{C} / \mathrm{min}$ and $50^{\circ} \mathrm{C} / \mathrm{h}$, respectively.

The structure and microstructure of the sintered materials were examined using X-ray diffractometry and scanning electron microscopy, respectively. The room temperature magnetic properties were obtained by recording hysteresis loops with the help of vibrating sample magnetometer. The initial permeability $\left(\mu_{\mathrm{i}}\right)$ of the toroidal sample was measured using HP 4191 impedance analyser in the frequency range $1-100 \mathrm{MHz}$. The power loss, $P_{\mathrm{h}}$ was measured at $100 \mathrm{kHz}-1 \mathrm{MHz}$ with flux density of $50 \mathrm{mT}$ using the B-H/Z analyser (HP-E5060A).

\section{Results and discussion}

From the X-ray diffraction patterns, it was found that the samples contained only single phase, irrespective of whether the materials were densified by the conventional or microwave sintering techniques. In both techniques the spinel formation is completed at a low temperature of $1050^{\circ} \mathrm{C}$. The average size of the ferrite grain, geometrically estimated from SEM photographs and results are presented in table 1. The grain size for MS and CS samples increases with increase in the sintering temperature. The grain size for the present samples varies from $17 \mu \mathrm{m}$ to $3.2 \mu \mathrm{m}$ and the grain sizes of MS samples are smaller than that of CS ferrites.

It can be seen from the table that the densification rate has been significantly increased in the microwave sintering process. In both preparation techniques the spinel ferrite formation is completed at a low temperature of $1050^{\circ} \mathrm{C}$. Conventional sintering process requires at least $21 \mathrm{~h}$ to reach the sintering temperature of $1050{ }^{\circ} \mathrm{C}$ and soaking time of $10 \mathrm{~h}$ to obtain sample with $92 \%$ of theoretical density (TD). The density of the samples increased to $94 \%$ of TD with an increase of sintering temperature from $1050^{\circ} \mathrm{C}$ to $1200^{\circ} \mathrm{C}$ and time taken was $34 \mathrm{~h}$. In contrast, the microwave sintering process needs only $25 \mathrm{~min}$ to reach $1050^{\circ} \mathrm{C}$ and a soaking period of $30 \mathrm{~min}$ to obtain a sample with density as high as $94 \%$ of TD. The density of MS ferrites has increased to $96 \%$ of TD with an increase of sintering temperature from 1050 to $1200^{\circ} \mathrm{C}$ and time of $60 \mathrm{~min}$. Thus, higher densification can be achieved in shorter period by using the microwave sintering process.

Saturation magnetization $\left(B_{\mathrm{s}}\right)$ and initial permeability $\left(\mu_{\mathrm{i}}\right)$ data obtained from recorded hysteresis loops are presented in table 1 . It can be seen from the table that the values of $B_{\mathrm{s}}$ and $\mu_{\mathrm{i}}$ are found to increase with increase in the sintering temperature. It is also observed that the microwave sintered samples yield greater magnetization and greater permeability than that of CS samples. The linearity between the sintering density and magnetization implies that the magnetization is conserved and that magnetization has little change at the sintering conditions. The initial permeability of the MS samples varies with sintering temperature in a similar way to that of the conventionally sintered samples, i.e. the higher the density, the larger the $\mu_{\mathrm{i}}$ value.

Figure 1 gives the a.c. resistivity as a Cole-Cole plot for $\mathrm{Mn}-\mathrm{Zn}$ ferrites obtained using microwave-sintered method. Similar results were observed for CS samples

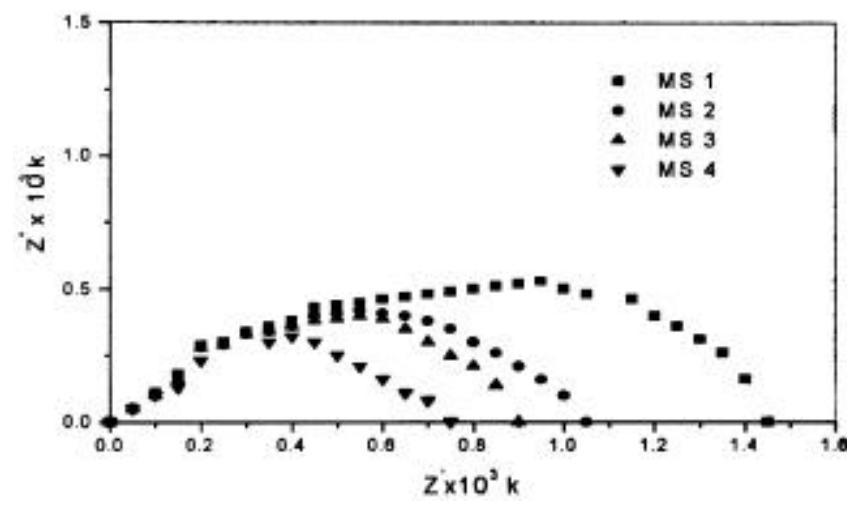

Figure 1. Cole-Cole of impedance for MS Mn-Zn ferrites.

Table 1. Preparation and magnetic properties data for $\mathrm{Mn}-\mathrm{Zn}$ ferrites at room temperature.

\begin{tabular}{lccccc}
\hline $\begin{array}{l}\text { Sample } \\
\text { no. }\end{array}$ & $\begin{array}{c}\text { Sintering } \\
\text { temp./time }\end{array}$ & $\begin{array}{c}\text { \% Theor. density } \\
(\mathrm{TD})\end{array}$ & $\begin{array}{c}\text { Grain size } \\
(\mu \mathrm{m})\end{array}$ & $\begin{array}{c}B_{\mathrm{s}} \\
(\mathrm{mT})\end{array}$ & $\begin{array}{c}\mu_{\mathrm{i}} \\
(1 \mathrm{MHz})\end{array}$ \\
\hline $\mathrm{CS} \mathrm{1}$ & $1050^{\circ} \mathrm{C} / 10 \mathrm{~h}$ & $92 \cdot 0$ & $9 \cdot 2$ & 475 & 1420 \\
$\mathrm{CS} \mathrm{2}$ & $1100^{\circ} \mathrm{C} / 10 \mathrm{~h}$ & $92 \cdot 6$ & $10 \cdot 0$ & 480 & 1500 \\
$\mathrm{CS} \mathrm{3}$ & $1150^{\circ} \mathrm{C} / 10 \mathrm{~h}$ & $93 \cdot 4$ & $12 \cdot 0$ & 495 & 2100 \\
$\mathrm{CS} \mathrm{4}$ & $1200^{\circ} \mathrm{C} / 10 \mathrm{~h}$ & $94 \cdot 1$ & $17 \cdot 0$ & 510 & 2250 \\
MS 1 & $1050^{\circ} \mathrm{C} / 30 \mathrm{~min}$ & $94 \cdot 3$ & $3 \cdot 2$ & 515 & 1850 \\
MS 2 & $1100^{\circ} \mathrm{C} / 30 \mathrm{~min}$ & $95 \cdot 3$ & $4 \cdot 5$ & 528 & 2200 \\
MS 3 & $1150^{\circ} \mathrm{C} / 30 \mathrm{~min}$ & $93 \cdot 6$ & $5 \cdot 3$ & 535 & 2500 \\
MS 4 & $1200^{\circ} \mathrm{C} / 30 \mathrm{~min}$ & $96 \cdot 3$ & $5 \cdot 8$ & 543 & 2875 \\
\hline
\end{tabular}


also. With the help of Cole-Cole plots and the equivalent circuit calculation, the intercept of low frequency limit is equal to the summation of grain resistivities and grain boundary resistivity. Hence, these resistivities are computed and results are presented in table 2 . It can be seen from the table that the complex impedance analysis indicates that both the sintering techniques used for densifying the $\mathrm{Mn}-\mathrm{Zn}$ ferrite materials does not alter the grain and grain boundary resistivity of the samples. Highly conductive grain is produced in the presence of $\mathrm{Fe}^{+2}$, which leads to the hopping conduction in the octahedral $\mathrm{Fe}^{+3}$ sites. The grain boundary resistivity in the present samples may be due to the formation of insulating layer. The grain and grain boundary resistivity decreases with an increase of the sintering temperature.

The power loss $\left(P_{t}\right)$ for all samples was measured at $100 \mathrm{kHz}$ to $1 \mathrm{MHz}$ with $200 \mathrm{mT}$ and obtained results are plotted in figure 2. It can be seen from the figure that the power loss is markedly lower for the MS samples than that of conventionally sintered samples. The power loss for conventionally sintered samples increased with increase in the frequency. But the power loss for the microwave-sintered samples remains constant up to a frequency of $500 \mathrm{kHz}$ and increases for higher frequencies.

Figure 3 gives the plots of temperature dependence of power loss for all the Mn-Zn ferrites. The power loss for the CS and MS samples decreases with an increase in temperature and shows a minimum value at a temperature, which is denoted by $T_{\min }$ (Otsuki et al 1991). It is also observed that the $T_{\min }$ temperature coincides with the second peak maximum in the permeability-temperature curve (Vasudev 1996) of corresponding sample. The temperature gradient of power loss for the MS samples is smaller with high $T_{\min }$ temperature.

The power loss mainly consists of the hysteresis loss $\left(P_{\mathrm{h}}\right)$ and the eddy current loss $\left(P_{\mathrm{e}}\right)$. In the present investigation, the hysteresis loss and eddy current loss were derived from the plots of frequency dependence of power loss using the Inoue's (Inoue et al 1993) model. According to this model, the slope and intercept of each line of plot $P_{\mathrm{t}} / f$ vs frequency $(f)$, represent eddy current loss and hysteresis loss, respectively (Stopples 1980, 1996).
Table 2 gives the room temperature values of $P_{\mathrm{h}}$ and $P_{\mathrm{e}}$ obtained from power loss vs frequency curves for all the ferrites. It can be seen from the table that the values of $P_{\mathrm{h}}$ and $P_{\mathrm{e}}$ decreased with an increase of sintering temperature. The values of $P_{\mathrm{h}}$ and $P_{\mathrm{e}}$ are higher for CS samples than that of MS ferrites.

Figure 4 gives the plots of $P_{\mathrm{h}}$ vs temperature for CS and MS samples. It is evident from the figure that the $P_{\mathrm{h}}$ for all the samples decreases with an increase of temperature

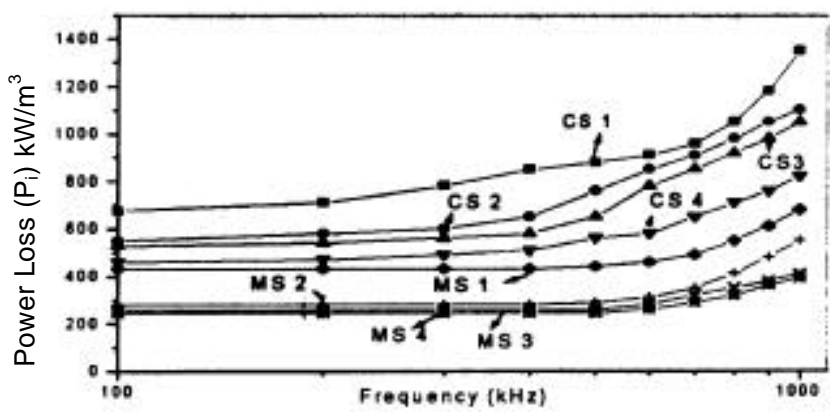

Figure 2. Frequency dependence of $P_{\mathrm{t}}$ for $\mathrm{Mn}-\mathrm{Zn}$ ferrites.

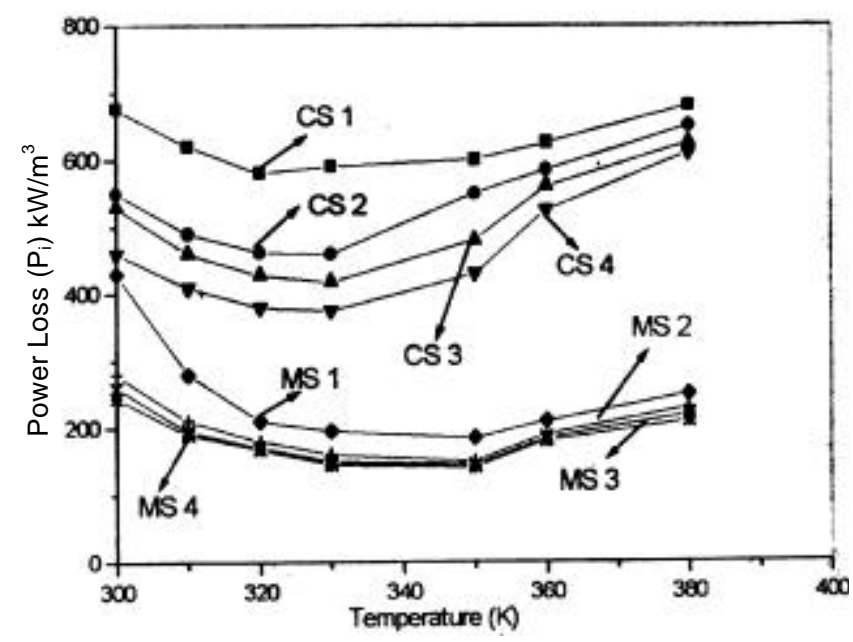

Figure 3. Temperature dependence of power loss for conventionally (CS) and microwave sintered (MS) Mn-Zn ferrites.

Table 2. Resistivity and power losses data for $\mathrm{Mn}-\mathrm{Zn}$ ferrites at room temperature.

\begin{tabular}{|c|c|c|c|c|c|}
\hline $\begin{array}{l}\text { Sample } \\
\text { no. }\end{array}$ & $\begin{array}{c}\text { Grain resistivity } \\
(\Omega-\mathrm{cm})\end{array}$ & $\begin{array}{c}\text { Grain boundary } \\
\text { resistivity } \\
(\Omega-\mathrm{cm})\end{array}$ & $\begin{array}{c}P_{\mathrm{t}} \\
\left(\mathrm{kW} / \mathrm{m}^{3}\right)\end{array}$ & $\begin{array}{c}P_{\mathrm{h}} \\
\left(\mathrm{kW} / \mathrm{m}^{3}\right)\end{array}$ & $\begin{array}{c}P_{\mathrm{e}} \\
\left(\mathrm{kW} / \mathrm{m}^{3}\right)\end{array}$ \\
\hline CS 1 & 1150 & $4.72 \times 10^{4}$ & 950 & 240 & 145 \\
\hline CS 2 & 1350 & $4.15 \times 10^{4}$ & 800 & 210 & 130 \\
\hline CS 3 & 1425 & $2.93 \times 10^{4}$ & 760 & 160 & 126 \\
\hline CS 4 & 1642 & $2.55 \times 10^{4}$ & 710 & 125 & 120 \\
\hline MS 1 & 1161 & $4.74 \times 10^{4}$ & 460 & 140 & 110 \\
\hline MS 2 & 1360 & $4.21 \times 10^{4}$ & 400 & 120 & 90 \\
\hline MS 3 & 1425 & $2.92 \times 10^{4}$ & 350 & 110 & 84 \\
\hline MS 4 & 1645 & $2.51 \times 10^{4}$ & 300 & 100 & 80 \\
\hline
\end{tabular}


and become flat above $360 \mathrm{~K}$. Hysteresis loss is known to be minimum at the secondary peak temperature, where the crystalline magnetic anisotropy is zero while the initial permeability is high (Vasudev 1996).

Temperature dependence of $P_{\mathrm{e}}$ for CS and MS samples are plotted in figure 5. It can be observed from the figure that the value of $P_{\mathrm{e}}$ for samples decreases with an increase of temperature and increases with further increase of temperature. The values of $P_{\mathrm{e}}$ for CS samples are much higher than that of MS samples and this result is in good agreement with literature values (Pyun and Baek 1985; Kim and Kwon 1992; Otsuki and Yamada 1995).

The electron transport mechanism in $\mathrm{Mn}-\mathrm{Zn}$ ferrites can be explained by electron hopping transport mechanism. In the electron hopping transport mechanism, the temperature dependence of the electrical resistivity is expressed by Arrhenius equation

$$
\rho=\rho_{0} \exp \left(Q / k_{\mathrm{B}} T\right)
$$

where $\rho_{0}$ is a constant, $Q$, the activation energy, $k_{\mathrm{B}}$ the Boltzmann constant and $T$ the temperature. The temperature dependence of the eddy current loss in $\mathrm{Mn}-\mathrm{Zn}$ ferrites on $\rho$ can be expressed as

$$
P_{\mathrm{e}}=K / \rho
$$

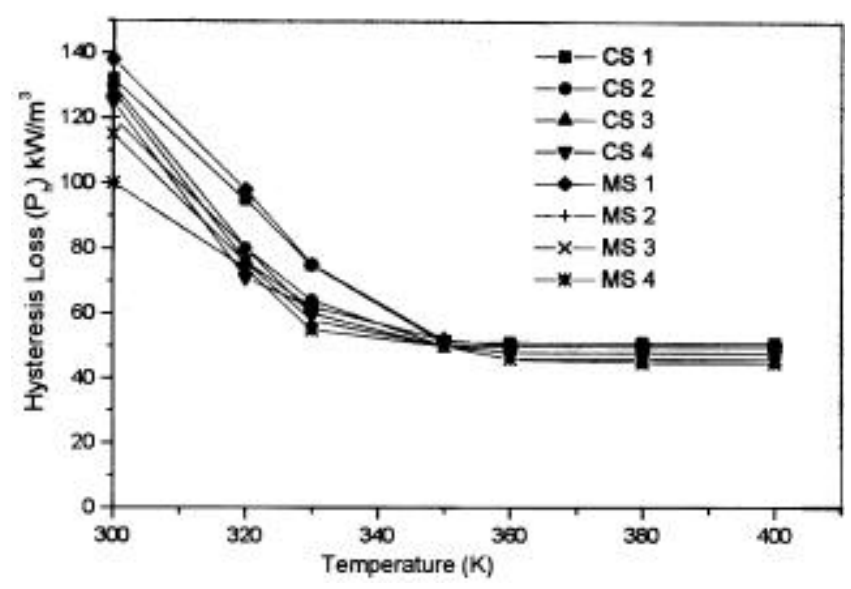

Figure 4. Temperature dependence of $P_{\mathrm{h}}$ for $\mathrm{Mn}-\mathrm{Zn}$ ferrites.

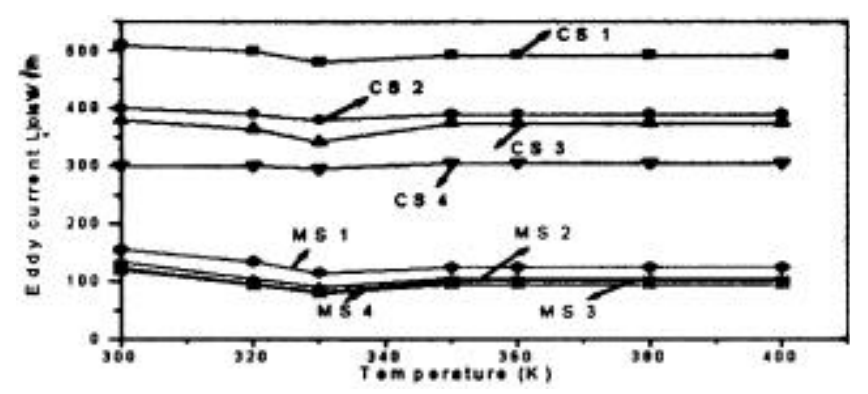

Figure 5. Temperature dependence of eddy current loss for CS and MS samples of Mn-Zn ferrites. where $K$ is a constant against $\rho$, depending on the magnetic domain structure, frequency and magnetic flux density (Otsuki and Yamada 1995). The temperature dependence of the eddy current loss is expressed as

$$
P_{\mathrm{e}}=k \exp \left(-Q / k_{\mathrm{B}} T\right) / \rho_{0} .
$$

Thus, the eddy current loss is also expressed by Arrhenius expression. The above (1) and (3) are used to compute the activation energies for the present $\mathrm{Mn}-\mathrm{Zn}$ ferrites. From the plots of temperature dependence of both eddy current loss and electrical resistivity, the activation energies are computed for MS and CS samples. The activation energies obtained from the plots of eddy current and electrical resistivity for the MS samples are $0.24 \mathrm{eV}$ and $23 \mathrm{eV}$, respectively. Similarly, the average activation energies for the CS samples are $0.24 \mathrm{eV}$ and $0.26 \mathrm{eV}$. In both cases the activation energies are found to be nearly equal. Therefore, the temperature dependence of eddy current loss in the present samples may be due to the change in the electrical resistivity with temperature.

\section{Construction of transformer}

The conductor-embedded-type transformers (Yamaguchi et al 1992) were constructed using the samples MS 4 and CS 4, which possess high density and low power losses. A ratio of the primary and secondary windings is taken as $2: 1$. These windings were made of a copper foil and separated by polymer insulator. The primary and secondary coils were arranged in the ferrite core and the height of the transformer was $4 \mathrm{~mm}$. The minimized flux leakage, uniform flux density and current density were achieved by having a closed conductor within the ferrite (Sasada et al 1993). Efficiency and temperature rise of the constructed transformers were measured with an input of sinusoidal voltage of $25 \mathrm{~V}$ at frequency $1 \mathrm{MHz}$ varying current by changing the load resistance.

Figures 6 (a)-(c) give plots of output power $(P)$, efficiency $(\eta)$ and surface temperature rise $(\Delta T)$ as a function of output current $(I)$ for both the transformers (MS-T and CS-T). It can be observed from the figure that the transformer (MS-T) made of MS ferrite exhibit a high efficiency more than $96 \%$ at output power of $12 \mathrm{~W}$. Similarly, $\Delta T$ of both the transformers increases with an increasing current, because of the increase of copper losses. It can be observed from the figure that the $\Delta T$ for the transformer made with MS ferrite is about $15^{\circ} \mathrm{C}$ lower than that of the transformer (CS-T) made using CS ferrite irrespective of I. The high efficiency and a low $\Delta T$ in MS samples may be due to low power losses of the ferrites at $1 \mathrm{MHz}$. However, for safe operation of transformers, $\Delta T$ is limited in the transformer design (Yamashita et al 1995). It is evident from the figure that at the same level of $\Delta T, 40^{\circ} \mathrm{C}$, the power capacity of the MS-T is $40 \%$ larger than that of CS-T. Thus, a ferrite with fine grains and 

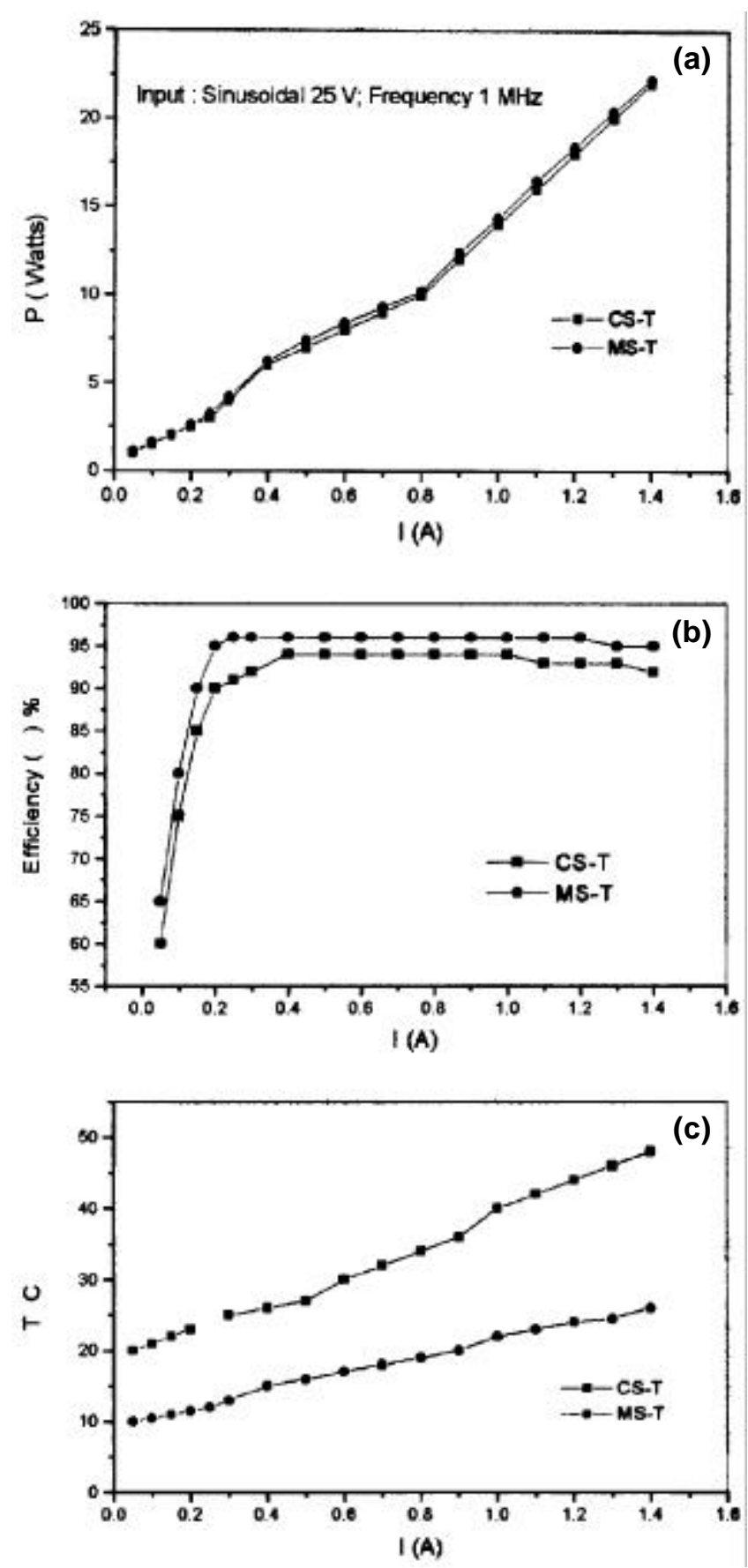

Figure 6. (a)-(c). Plots of output power $(P)$, efficiency $(\eta)$ and rise in surface temperature $(\Delta T)$ for the transformers (CS-T and MS-T) as a function of output current $(I)$.

low power losses is more effective in obtaining a low profile and high-density switching converter.

\section{Conclusions}

We have developed the higher density $\mathrm{Mn}-\mathrm{Zn}$ ferrites with low power losses as compared with the conventional Mn$\mathrm{Zn}$ ferrite at a frequency range from $10 \mathrm{~Hz}$ to $1 \mathrm{MHz}$. The transformer constructed with ferrite sintered using microwaves shows high efficiency and low surface temperature rise at the driving frequency of $1 \mathrm{MHz}$ when compared with the transformer made using the conventionally sintered ferrite.

\section{Acknowledgements}

The financial support received from the Department of Science and Technology, New Delhi, and DRDO, New Delhi, is gratefully acknowledged. The author is grateful to Dr Swaminathan, Scientist, R\&D Division, BHEL, Hyderabad, for providing microwave sintering facilities.

\section{References}

Globus A 1977 Proc. J. Phys. Colloq. 38 C1

Goldman A 1990 Modern ferrite technology (New York: Van Nostrand)

Inoue O, Matsutani N and Kugimiya K 1993 IEEE Trans. Mag. 293532

Kim You Song and Kwon S J 1992 Proc. ICF 6 (Kyoto: Japan Soc. of Powder Metallurgy) p. 37

Lee Ki-youg and Case D 1999 Mater. Sci. \& Engg. A269 8

Lin C H, Chang H Y and Lin I N 1997 IEEE Trans. Magn. 33 3415

Otsuki D E and Yamada Y 1995 Mag. Ceram. 47147

Otsuki E, Otsuka $\mathrm{T}$ and Sato $\mathrm{T} 1991$ J. Appl. Phys. 69 3942

Pyun S I and Baek J T 1985 Am. Ceram. Soc. Bull. 64602

Ruginets R and Fischer R 1995 Am. Ceram. Bull. 7456

Sasada I, Yamaguchi T, Harada K and Notohara Y 1993 IEEE Trans. Magn. 29323

Snelling E C and Giler A D 1983 Ferrites for inductors and transformers (London: Research Studies Press Ltd) p. 51

Stopples D 1980 J. Appl. Phys. 512789

Stopples D 1996 J. Magn. Magn. Mater. 160323

Vasudev B 1996 Electrical and elastic properties of Mn-Zn ferrites, Ph.D Thesis, Osmania University, Hyderabad

Yamaguchi Y, Sasada I and Harada K 1992 J. Magn. Soc. Jpn. 16445

Yamashita N, Murakami N and Yachi T 1995 Proc. IEEE 10th applied power electronics conf. (Tokyo: Tokyo University Press) p. 297

Yasuhara K and Takagawa K 2000 Proc. ICF8 (Bordeaux, France) p. 54 